\title{
DESENVOLVIMENTO DO TRATAMENTO TÉRMICO DO VERGALHÃO CA50 EM ROLO PELO PROCESSO STELMOR*
}

\author{
José Raphael Olegário França' \\ Aline da Costa Miranda Lima ${ }^{2}$ \\ Jeferson Leandro Klug ${ }^{3}$
}

\section{Resumo}

Os vergalhões CA50 bitolas finas $8,00 \mathrm{~mm}$ a $16,00 \mathrm{~mm}$, em rolos produzidos via Stelmor são os produtos de maior demanda da CSN aços longos. Estes produtos sofrem tratamento térmico de resfriamento ao ar forçado via esteira transportadora de espiras, após serem laminados e espiralados. Devido a parâmetros e características do próprio processo o produto final apresentava heterogeneidade nas propriedades mecânicas que era causada por um resfriamento diferenciado das espiras, gerando reprovação na inspeção da qualidade. Através do uso de pirômetros para monitorar a temperatura das espiras e uma otimização do resfriamento com defletores do fluxo de ar ao longo da esteira transportadora, tornou-se possível reduzir a heterogeneidade das propriedades mecânicas, assim como a elaboração de ferramentas que ajudam na parametrização do Stelmor.

Palavras-chave: Stelmor; Resfriamento ao ar forçado; Vergalhão em rolo.

\section{DEVELOPMENT OF THE THERMAL TREATMENT OF BAR COIL CA 50 BY STELMOR PROCESS}

\section{Abstract}

The bar CA 50 thin gauges $8.00 \mathrm{~mm}$ to $16.00 \mathrm{~mm}$ in coils produced via Stelmor are the increased demand for long steel products CSN. These products undergo heat treatment Cooling air forced through spiral conveyor belt after being rolled and coiled. Because the parameters and characteristics of the final product process itself showed heterogeneity in mechanical properties that was caused by differential cooling of the coils, causing failure in quality inspection. Through the use of pyrometers to monitor the temperature of the coils and optimization with a cooling airflow baffles along the conveyor belt, it has become possible to reduce the heterogeneity of mechanical properties as well as in the development of tools that help the parameterization Stelmor.

Keywords: Stelmor; Cooling air forced; Bar coil.

Graduando em Eng. Metalúrgica, Universidade Federal do Ceará, Fortaleza, Ceará, Brasil.

M.Sc. em Engenharia Metalúrgica, Coordenadora Técnica da Gerência Técnica, CSN Aços Longos, Volta Redonda, RJ, Brasil.

3 D. Sc. Professor Associado, Universidade Federal do Ceará, Fortaleza, Ceará, Brasil. 


\section{INTRODUÇÃO}

O funcionamento do Stelmor - esteira transportadora de espiras, vergalhão em rolo de bitolas finas ente $8,00 \mathrm{~mm}$ até $16,00 \mathrm{~mm}$, tem como função transportar as espiras após o formador de espiras, por uma esteira de rolos com velocidade regulável, que permite uma variação na densidade do arranjo das espiras depositadas na esteira. Sob a esteira transportadora há ventiladores centrífugos de alta capacidade instalados para que haja um resfriamento ao ar das espiras. Existem caixas de água anteriores ao formador de espiras com a função de homogeneizar e controlar a temperatura de entrada das espiras na esteira. Após a passagem pelas caixas de água o vergalhão ainda reto chega ao formador de espiras onde é espiralado e lançado sobre a esteira transportadora de espiras, Stelmor. Localizado após o formadora de espiras, a esteira transportadora, é onde as propriedades metalúrgicas desejadas são obtidas através do tratamento de normalização ao ar forçado e as propriedades metalúrgicas desejadas são obtidas. Então, o vergalhão segue para a estação reformadora onde as bobinas são recolhidas e enviadas em ganchos para 0 empacotamento $[1,3]$.

No presente trabalho são apresentadas as principais características do resfriamento das espiras, bem como as heterogeneidades, de acordo com os parâmetros utilizados no equipamento, além da elaboração de curvas de resfriamento do equipamento. Com tais ferramentas, são apresentadas melhorias técnicas de produção e qualidade para o desenvolvimento do vergalhão CA50 bitolas finas em rolo via Stelmor com aço microligado produzido na nova unidade CSN, como também, obter controle e conhecimento do processo, objetivando reduzir tais heterogeneidades e visando atingir a norma NBR 7480, que trata de aços para armadura de construção civil.

\section{MATERIAIS E MÉTODOS}

Para a realização deste trabalho foram utilizadas amostras de vergalhão CA50 de $\varnothing$ $8,00 \mathrm{~mm}$, grau de Aço 1635 microligado ao vanádio com $0.36 \%$ a $0.40 \%$ de carbono e alto teor de manganês, acima de um por cento.

Foram analisadas três bobinas do vergalhão e retiradas três espiras de cada, uma na cabeça da bobina, uma no meio e outra na calda (Figura 1). Cada espira foi cortada, dividida em diversos pedaços, cerca de $40 \mathrm{~cm}$ e endireitadas, conforme esquema a baixo (Figura 2), para realização de ensaios mecânicos. 

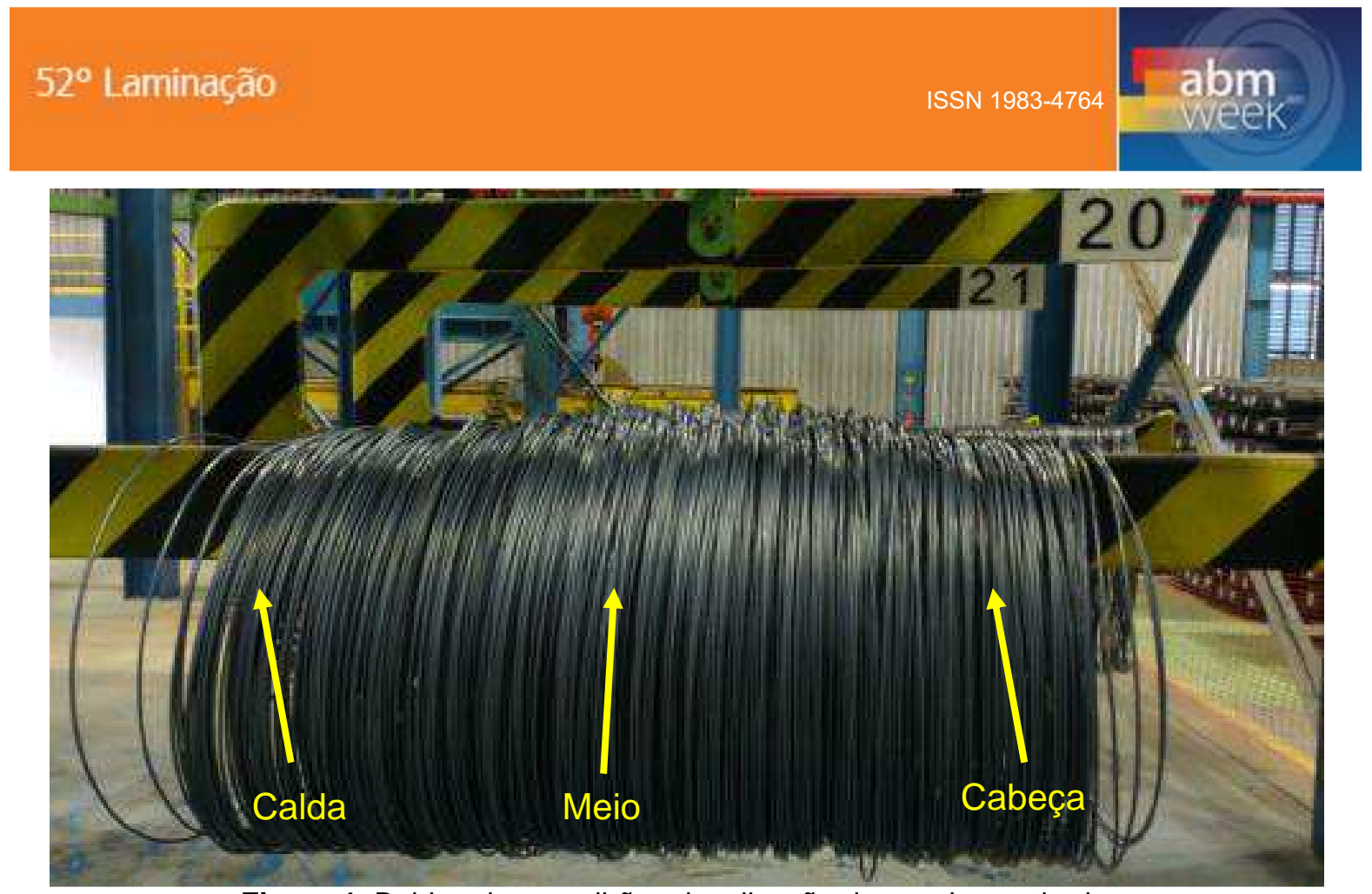

Figura 1. Bobina de vergalhão e localização das espiras retiradas.

Com o diâmetro da espira em torno de $100 \mathrm{~cm}$, após endireita-las, ficando com 314 $\mathrm{cm}$ de comprimento para cada espira retiradas. Com amostras de $40 \mathrm{~cm}$ de comprimento, gerou-se sete amostras por espiras, totalizando 63 amostras nas três bobinas.

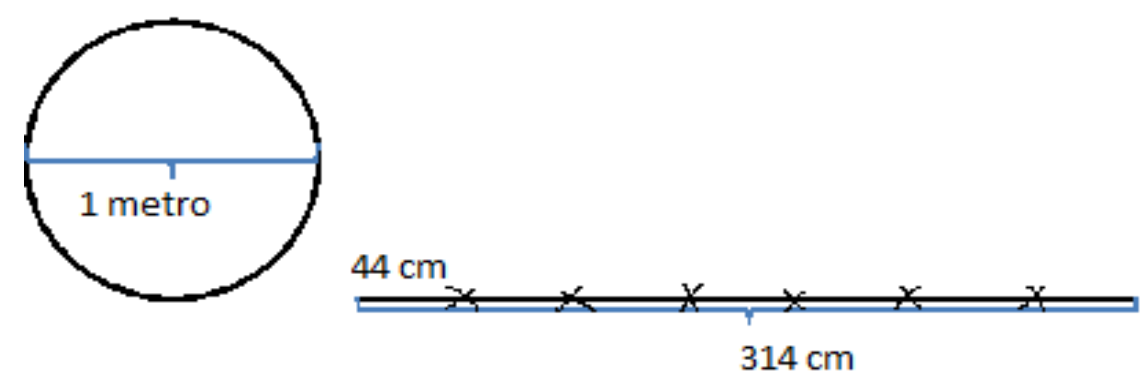

Figura 2. Esquema de endireitamento e corte de amostras.

Todas essas amostras foram ensaiadas na máquina de tração, assim como no teste de dobramento semi guiado de acordo com as normas NBR ISO 6892 e NBR 6153 respectivamente.

Realizou-se metalografias de algumas amostras antes de serem ensaiadas mecanicamente. Os corpos de prova foram seccionados em uma máquina de corte com disco de $2 \mathrm{~mm}$ de espessura em refrigeração através de fluido abundantemente para evitar o aquecimento e consequentemente alteração microestrutural. Todas as amostras foram embutidas em baquelite, lixadas, polidas e atacadas obedecendo aos procedimentos de preparação de amostras metalográficas via microscopia ótica. O desbaste grosseiro foi realizado em lixas sequenciais com granulometria de 220 mesh, 400 mesh, 600 mesh e 1.200 mesh e a preparação final em politriz dotada de prato giratório com pano fino utilizando pastas de diamante $4 \mu \mathrm{m}$ e $2 \mu \mathrm{m}$ para obtenção de uma superfície espelhada e livre de deformações. As amostras de aço foram submetidas a ataque químico com 0 reativo Nital $3 \%$, durante 
aproximadamente 10 segundos para a revelação da microestrutura. Todos esses ensaios foram realizados no laboratório de ensaios mecânicos da CSN - Aços Longos.

Para a elaboração das curvas de resfriamento, utilizou-se pirômetros portáteis de mão com capacidade de ler temperaturas de $400^{\circ} \mathrm{C}$ a $1600^{\circ} \mathrm{C}$ e de $100^{\circ} \mathrm{C}$ a $600^{\circ} \mathrm{C}$. Mediu-se as temperaturas ao longo da esteira transportadora de espiras, local onde ocorre o resfriamento ao ar forçado, a cada 5 metros começando pelo formador de espiras.

\section{RESULTADOS E DISCUSSÃO}

Dos resultados obtidos dos ensaios mecânicos (Tabela 1), notou-se uma heterogeneidade dentro do mesmo produto, mesmo sendo produzido sob os mesmos parâmetros de produção. Assim como os resultados dos ensaios obtidos anteriormente, realizados pelos técnicos do laboratório de ensaios mecânicos durante a produção do vergalhão, apresentou-se variações nos limite de escoamento, limite de resistência e alongamento dentro de uma mesma espira.

Tabela 1. Resultados das sete amostras de uma cauda

\begin{tabular}{ccccc}
\hline Amostra & L.E.(Kgf/ $\left.\mathbf{m m}^{2}\right)$ & L.R.(Kgf/ $\left.\mathbf{m m}^{2}\right)$ & Al.(\%) & L.R./L.E. \\
\hline 1 & 73,7 & 89,5 & - & 1,214 \\
\hline 2 & 56,2 & 87,7 & - & 1,560 \\
\hline 3 & 60,6 & 91,7 & 8,9 & 1,513 \\
\hline 4 & 68,2 & 91,2 & - & 1,337 \\
\hline 5 & 67,3 & 88,6 & 8,4 & 1,316 \\
\hline 6 & 77,2 & 89,5 & 6,3 & 1,159 \\
\hline 7 & 65,0 & 90,8 & 7,4 & 1,397 \\
\hline
\end{tabular}

L.E: limite de escoamento; L.R: limite de resistência; AL: alongamento.

Nos testes de dobramento tiveram amostras reprovadas e aprovadas dentro de uma mesma espira e sob os mesmos parâmetros de produção.

Através de análises metalográficas do produto (Figura 3), observou-se também uma heterogeneidade da microestrutura e que o aço microligado ao vanádio tem uma alta sensibilidade à taxa de resfriamento, formando bainita (Figura $3 \mathrm{~b}$ ) com resfriamento ao ar forçado como também perlita em redes de ferrita (Figura 3a) [2].
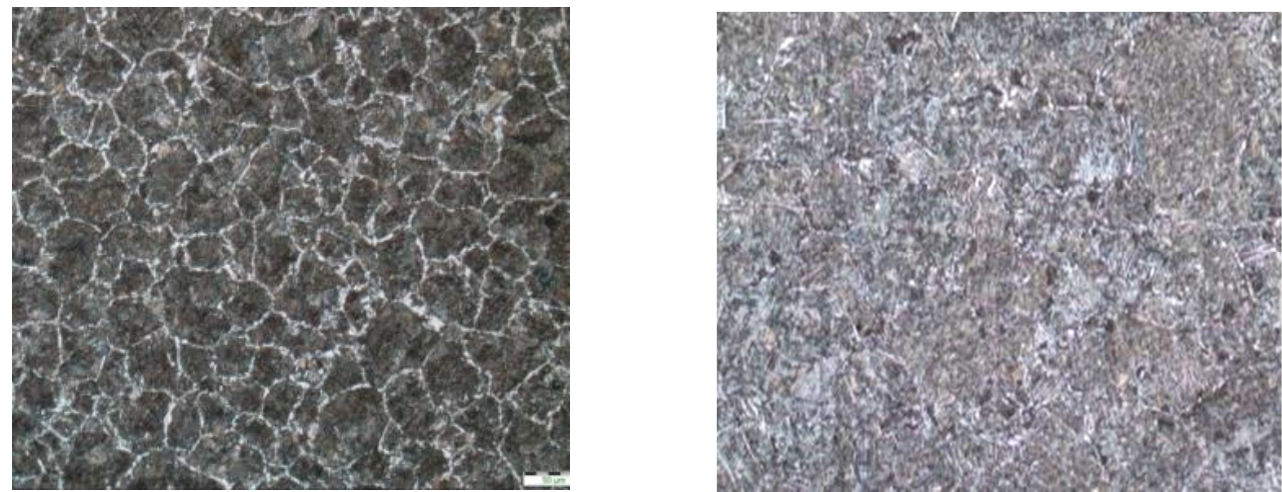

Figura 3. (a) llustra a presença de perlita em redes de ferrita. Aumento: 200x; (b) Aspecto da microestrutura llustrando a formação de bainita. Aumento: 200x. 


\subsection{Causas das Heterogeneidades}

Analisou-se, in loco, as variáveis do processo da esteira transportadora de espira, observou-se uma variação de resfriamento durante o processo, onde as regiões laterais permaneciam mais incandescentes ao longo da esteira do que as regiões centrais, gerando essas variações de propriedades mecânicas.

Elaborou-se, posteriormente, um esquema gráfico que simula o rolo ao longo da esteira (figura 4). Recortou-se um elemento que se repete de modo que represente 0 comportamento das espiras como um todo e o dividiu em zonas para analisar possíveis diferenças entre as mesmas $[1,3]$.

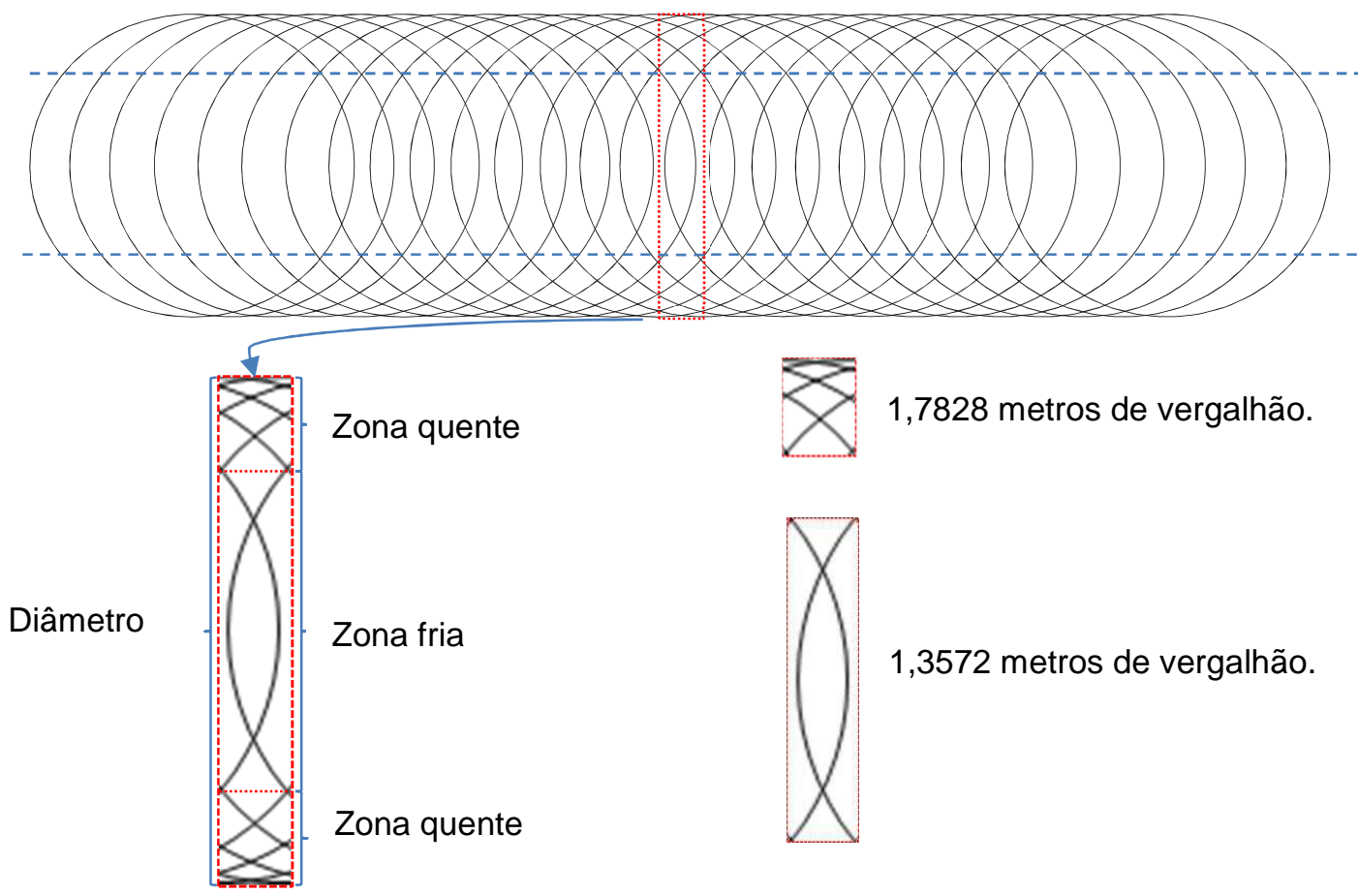

Figura 4. Esquema ilustrativo do rolo na esteira transportadora com seu elemento representativo e a divisão em zonas.

Visualmente percebe-se que a área das zonas laterais tem uma maior densidade de material e com as medidas feitas em cada zona, mostrou-se realmente que as zonas laterais tem maior quantidade de material do que a zona central. ${ }^{(1)}$ Consequentemente a capacidade térmica, que é diretamente proporcional à quantidade de massa, também será maior nas regiões laterais do que na região central, gerando variação de resfriamento entre as mesmas, com regiões de maior taxa de resfriamento (região central) e regiões de menor taxa de resfriamento (regiões laterais). Assim as propriedades mecânicas variam de região para região. As amostras da região central por receber maior resfriamento terão maiores propriedades mecânicas (L.E. e L.R.) do que as regiões laterais que recebem menor resfriamento gerando menores propriedades mecânicas (L.E. e L.R.).

Outro fator importante gerador de heterogeneidade nas propriedades mecânicas é que o aço microligado ao vanádio tem uma alta sensibilidade à taxa de resfriamento (Figura 5). 
Conforme a curva CCT do aço microligado ao vanádio, notou-se realmente o quanto ele é sensível ao resfriamento, com o campo da ferrita e perlita muito afastados, enquanto os campos da martensita e bainita são próximos e grandes [2,6].

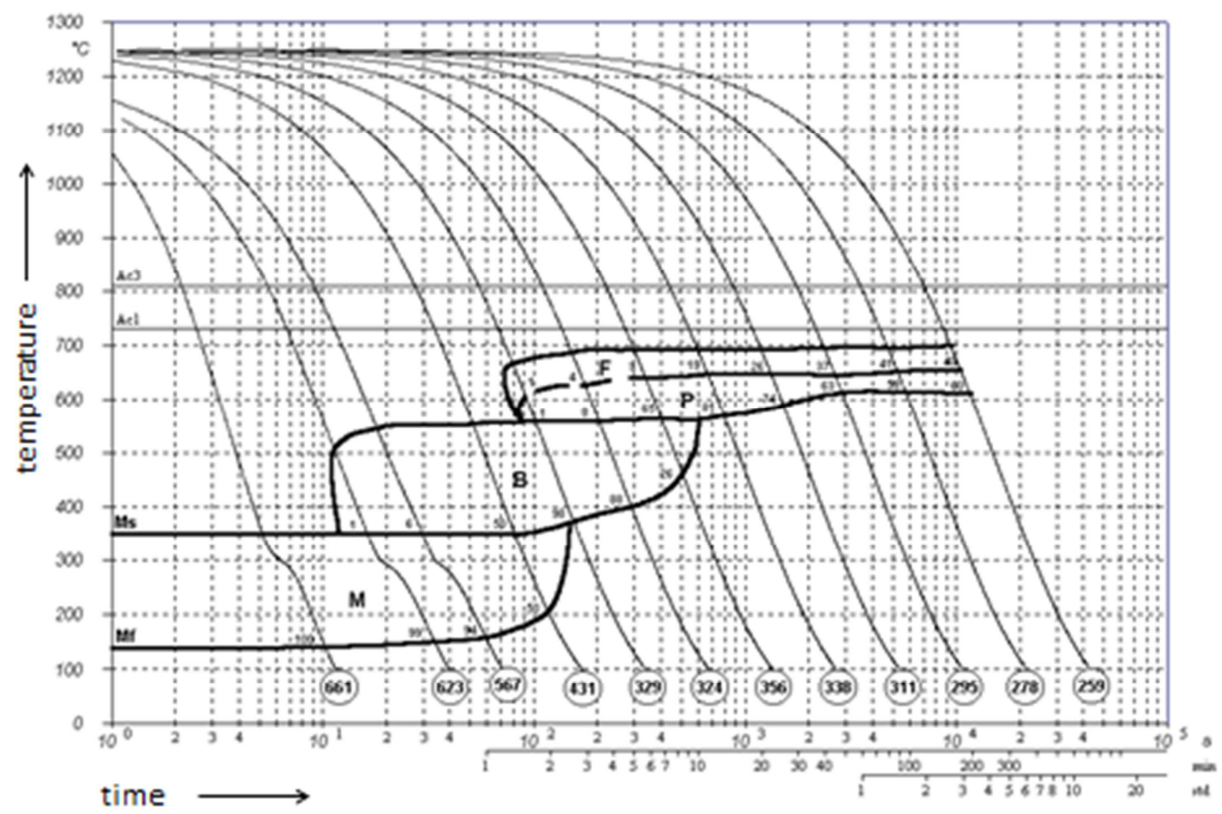

Figura 5. CCT do aço microligado ao vanádio [6].

\subsection{Perfil Térmico da Esteira e Sua Melhoria}

Medições das temperaturas realizadas alinhada com o meio da esteira com a utilização de pirômetro comprovaram a variação de temperatura entre as zonas (Figura 6). Observou-se diferença entre as zonas de $100^{\circ} \mathrm{C}$ a $200^{\circ} \mathrm{C}$ na temperatura do material e de acordo com a CCT do aço, pode-se obter microestruturas totalmente diferentes, que consequentemente gera propriedades mecânicas totalmente distintas.

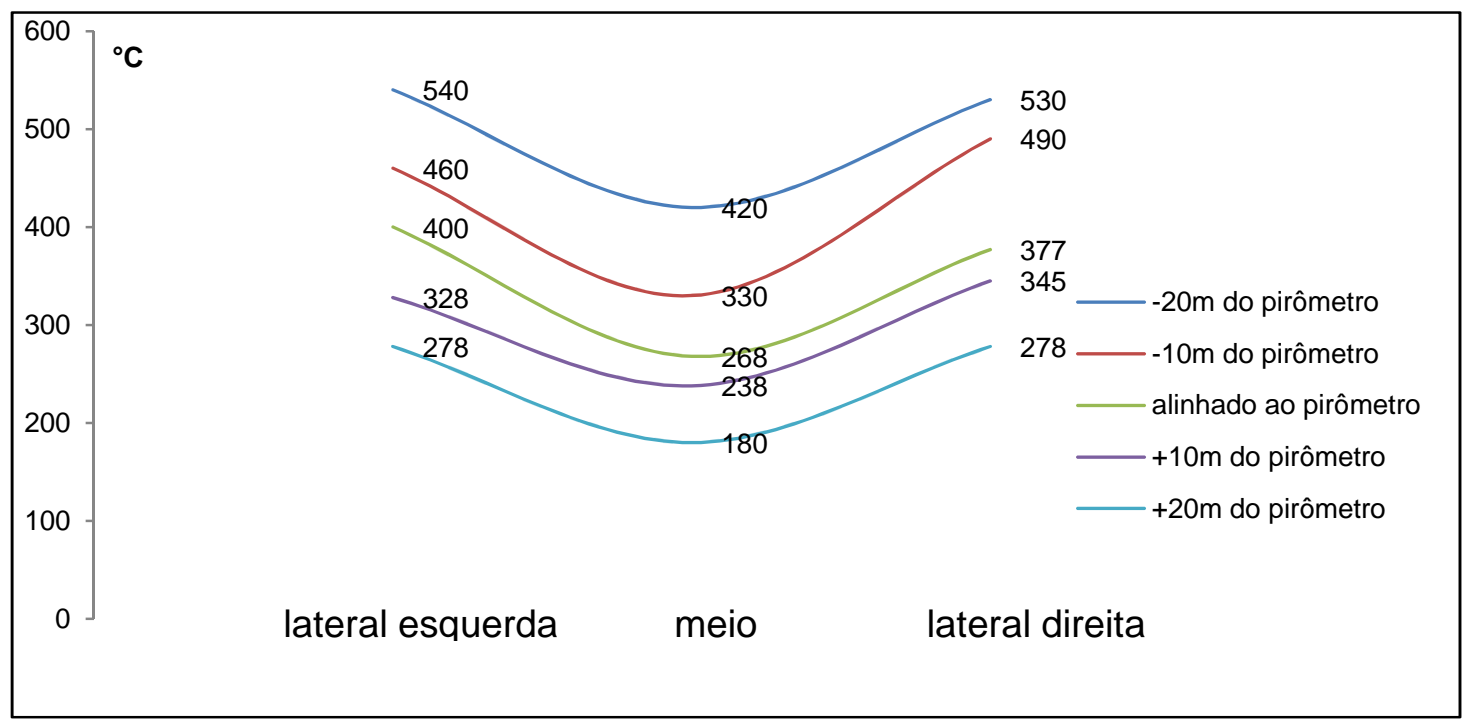

Figura 6. Variação da temperatura entre as zonas ao longo da esteira. 
Devido a maior quantidade de calor nas regiões laterais, torna-se necessário uma maior quantidade de ventilação para estas regiões de modo a equilibrar a taxa de resfriamento entre as zonas, por conseguinte, a obtenção de propriedades mecânicas mais homogêneas. Buscou-se, então, direcionar o fluxo de ar dos ventiladores através dos dampers, palhetas do ventilador que ajuda a direcionar 0 fluxo de ar, para as regiões laterais com pelo menos $31 \%$ a mais de ventilação do que a zona fria, conforme a relação entre a zona lateral e a zona central.

$$
\frac{\text { Zona lateral }(1,7828 \mathrm{~m})}{\text { Zona central }(1,3572 \mathrm{~m})}=1,31
$$

\subsubsection{Melhorias}

Ajustou-se o equipamento conforme descrito acima, também realizou-se novas medições das zonas laterais e centrais, o gráfico seguinte ilustra a nova configuração entre as zonas. Observou-se uma redução na diferença de temperatura de $200^{\circ} \mathrm{C}$ para $100^{\circ} \mathrm{C}$ aproximadamente, consequentemente uma redução na variação das propriedades mecânicas entre as zonas, gerando uma maior homogeneidade do produto e por consequência uma redução na reprovação do produto junto à equipe da qualidade.

Para maior controle e conhecimento do processo, desenhou-se as curvas de resfriamento ao longo da esteira transportadora (Figura 7). A cada 5 metros da esteira registrou-se uma medida das zonas com a utilização de pirômetro, afim de ter um maior conhecimento em relação à taxa de resfriamento, temperatura de transformação de fase e microestrutura obtida de acordo com a CCT do aço [4].

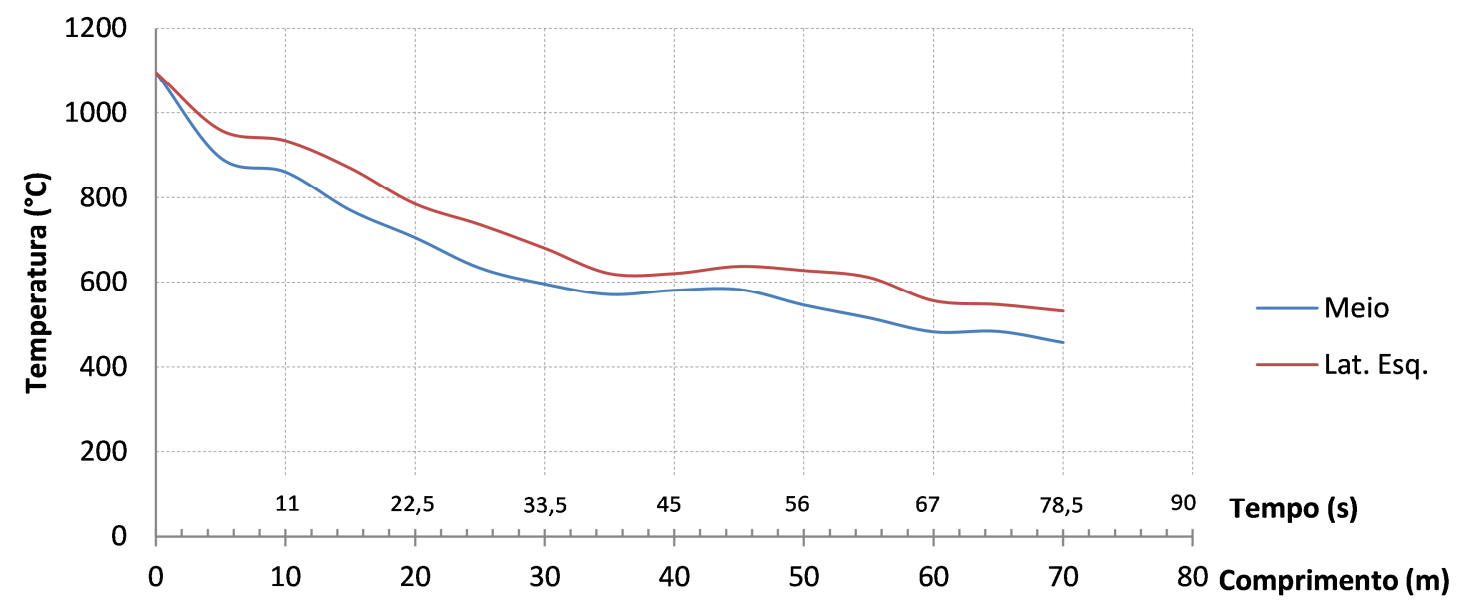

Figura 7. Curva de resfriamento ao longo da esteira com as temperaturas das zonas e tempos.

De acordo com o gráfico, entre $580^{\circ} \mathrm{C}$ a $630^{\circ} \mathrm{C}$ ocorre um aumento da temperatura que corresponde a uma transformação de fase. Assim, a cinética da decomposição da austenita pode ser analisada. Essa recalescência acentuada é caracterizada pela transformação da austenita em perlita $[1,5]$. 


\section{CONCLUSÃO}

Neste trabalho, buscou-se a elaboração de ferramentas para conseguir um maior conhecimento e controle do processo, uma vez que assim, pode-se atingir as microestruturas desejadas e consequentemente as propriedades mecânicas resultantes pelo uso de determinadas taxas de resfriamento. Essas ferramentas também são muito importantes para uma boa parametrização da abertura dos ventiladores, pode-se atingir estruturas $100 \%$ bainíticas, com alta ventilação, ou então, sem nenhuma ventilação pode-se atingir estrutura perlítica arrodeada de ferrita.

As causas das heterogeneidades do vergalhão em rolo foram demonstradas que estavam ligadas a característica do processo em si, que por sua vez gerava um resfriamento diferenciado entre as regiões. A diferença de temperatura entre as zonas, após a modificação do fluxo de ar em 31\% a mais para as regiões laterais, conseguiu-se uma redução de $200^{\circ} \mathrm{C}$ para menos de $100^{\circ} \mathrm{C}$, essa redução trouxe uma homogeneidade maior das propriedades mecânicas, reduzindo-se as perdas por reprovação do material. Finalmente, o enquadramento do produto vergalhão em rolo CA50 Ø 8,00 mm dentro da norma NBR 7480, que trata de aços para armadura de construção civil.

\section{Agradecimentos}

Os autores gostariam de agradecer à CSN pela oportunidade de estágio assim como à UFC e ao Prof. Dr. Lindberg Lima Gonçalves (Professor titular da UFC) na articulação para a realização do estágio.

\section{REFERÊNCIAS}

1 Campbell, P.C., Application of microstructural engineering to the controlled cooling of steel wire rod, A Thesis for the Degree of Doctor of Philosophy, The University of British Columbia, 1989.

2 Bhadeshia, H.K.D.H., Honeycombe, R.W.K., Steels: Microstructure and Properties, third ed. Butterworth-Heinemann, London; 2006.

3 Hanada, Y., Ueno, K., Noda, A., Kondoh, H., Sakamoto T. and Mine K., New Type Stelmor Equipamento of Wire Rod and Bar Mill, Kawasaki Steel Technical Report, (15), p. 50-57. (1986).

4 Rizzo, E. M. S. Processos de Laminação de Produtos Longos de Aço. São Paulo, ABM, 2007.

5 Campbell, P.C., Hawbolt, E.B. and Brimacombe, J.K., Microstructural Engineering Applied to the Controlled Cooling of Steel Wire Rod- Part III. Experimental Design and Heat Transfer, Met. Trans., 22A, pp. 2769-2778, (1991).

6 Vanadium International Technical committee, Transformation Diagrams for Vanadium Steels, Vanitec, (1985). 